\title{
Prevention is better than...?
}

\author{
Stephen Hancocks OBE \\ Editor-in-Chief
}

The BDJ Upfront section includes editorials, letters, news, book reviews and interviews. Please direct your correspondence to the News Editor,

Kate Quinlan at BDJNews@nature.com. Press releases or articles may be edited, and should include a colour photograph if possible.

A s a child I remember puzzling for a long time over what turned out to be a joke but which was posed seemingly as a question: 'if smoking is so bad for you how come it cures fish?' Firstly, I didn't know that fish smoked or could get sick from it and secondly that curing has two distinctly different meanings. Once it was explained I sort-of understood, although frankly then, as now, it is not especially clever or funny.

I mention it because the word 'cure', as in 'prevention is better than', is familiar enough in many circumstances in life but with a particular resonance for us in oral health. As is commonly expressed, what a strange professional furrow it is that we plough when in essence as far as prevention is concerned we are working to put ourselves out of business. The difficulty with prevention is in proving it. Evidence-base is the current bedrock upon which everything we do is ideally founded and yet the absence of something, anything, is difficult to prove. How does one convince that an action has specifically prevented something? Comparison is one way; a community with fluoridated water has about half the caries experience of another without an appropriately adjusted supply. But at an individual level how does that proof work? And, as importantly, how does one pay for it, or get paid to provide it? A central tenet of the endlessly discussed next NHS dental contract is prevention but there are few if any systems in the world which are geared to effectively reward prevention in the form with which we are most familiar, namely fee for item of service, or fee for proven work completed.

For many years I have teased about how as dentists we seem unable to define a hole, a cavity. Increasingly, in a world of minimally interventive therapy the definition will become more and more difficult; when does demineralisation become a frank lesion? However, in my moments of merrily joshing about such apparent inability to demarcate one of our core activities what I had completely overlooked was our similar handicap of being able to agree on what is prevention. The realisation was partly prompted by a paper in this issue on the use of prevention in the Norwegian public dental service. ${ }^{1}$ Whilst not, perhaps, an immediately obvious trigger what struck me was that even in a Scandinavian country with a long tradition of preventive philosophy and application at the chairside there is a lack of consistency and agreement as to what is implemented and indeed what is effective. Somewhat sobering.

So, we are all agreed that prevention is a good thing but what form should it take and where is the proof? It has to be about very knowledgeable and we need their advice over the technicalities of the law. But why do we think differently about health, about the technicalities of prevention? Demonstrably, we value it less and that is a conundrum as well as a sadness. A comment on the human condition.

It does not alter the fact that on the level of providing a one-to-one preventive service what is needed most is understanding and time spent. There is no magic one size fits all, no universal panacea. We have laudably distilled guidance in publications such as The scientific basis of oral health education and Delivering better oral health but the application of that knowledge requires interpretation and relevant advice and action either on the part of the professional or the patient.

\section{A \\ 'How does one convince that an action has specifically prevented something?'}

individual advice for each person and each separate situation. The general press has recently had a field day on the matter of dental floss. Given that it is the silly season in which there is a dearth of news and the media latches on to almost any story to fill column inches and to pad out time, a story that there is no evidence that floss prevents caries or periodontal disease is a gift. What was not said was that using floss does remove plaque, as it quite obviously does, but it needs further explanation, it needs time; and time is what we often do not have with our patients. We anticipate that lawyers, for example, charge high fees and earn a lot of money because they are
If we are serious as a society in believing in better health and specifically better oral health we have also to allocate the appropriate resources, money and time, to them; which includes spending them on prevention. It has long been our ethos to promote prevention over cure but if we are to continue to make headway we will have to alter our perception of its value in order to change that in our patients. If we can agree that prevention is better than cure how is it that we cannot agree on how?

DOI: 10.1038/sj.bdj.2016.578

1. Widström E et al. Chair-side preventive interventions in the Public Dental Service in Norway. Br Dent J 2016: 211: 179-185. 